\title{
Green Buildings - sustainable development strategy
}

\author{
Yury Tabunshchikov ${ }^{1}$, Marianna Brodach $^{1}$, Nikolay Shilkin ${ }^{1, *}$ \\ ${ }^{1}$ Moscow Institute of Architecture (State Academy) MARKHI, 11, Rozhdestvenka street, 107031, \\ Moscow, Russia
}

\begin{abstract}
Green construction is one of the most promising directions for development not only in the construction complex, but also in the social environment. Green buildings, as human environment, are attractive for investors, designers, utility equipment manufacturers and housing owners. Requirements for green buildings are sufficiently high and cannot be met by the traditional design principles based mainly on typical solutions. As a result we need to arm designers, builders and operators with new creative knowledge. In essence certification of a facility as a green building initiates a creative search for architects and engineers of such technical solutions that minimize negative and optimize positive influence of energy, environmental and technological factors that define the building as human environment. In this work it is difficult to separate the creativity of architect and engineer: we have to consider their joint work during the entire design process and only such union can bring success in achievement of the set goal.
\end{abstract}

\section{Introduction}

The term "green buildings" generally accepted in the global practice means the construction of energy-efficient, environmentally sustainable buildings with the maximum use of renewable energy resources and high comfort of the human environment.

The term "building as a human environment" refers not only to the building object itself, but to everything else, which includes the concept of "environment", specifically: the presence of a park zone, sports and playgrounds, parking lots for cars and bicycles near the building, distance from public transport stations, etc.

The requirements for "green buildings" are quite high and cannot be satisfied with traditional design principles. As a result, there is a need to equip designers, builders and operators with new creative knowledge.

We can assume that to date, the foundations of the science of "green buildings" have already been created. And it is no surprise: "green buildings" are a systematic continuation of the development of energy-efficient buildings, smart buildings, bioarchitecture buildings, healthy buildings, etc.

\footnotetext{
* Corresponding author: doptaganka@yandex.ru
} 


\section{Main idea for the construction of the 21st century}

After the global energy crisis, an area called "construction of energy-efficient buildings" appeared in global construction practice, and the scientific foundations for designing such buildings began to develop rather intensively, which not only have not lost their relevance to the present, but the demand for which is constantly growing, only accents shift. Since the 1980 s, special attention has been paid to the environmental safety of houses and the quality of indoor air. The following regularity is formulated: among energy-efficient technologies, priority is given to those that contribute to improving the quality of internal air and improve the environmental safety of the house. Since the late 1990s, requirements for energy efficiency and environmental friendliness have been added to protect the environment from destruction. The main idea for the construction of the 21 st century is the provision that nature is not a passive background of our activity: as a result of a professional approach, a new natural environment can be created that has higher comfortable indicators for urban planning and is also an energy source for building climate control. The logic of the development of modern construction is the result of the desire for harmony of the natural environment surrounding the building and the indoor microclimate.

The question arises: "Do the architect and engineer need new knowledge to design a building that meets the requirements of the standards for "green buildings"?" We will try to briefly answer this question by considering the requirements of the rating system for assessing "green buildings" in terms of increasing their energy efficiency.

\section{Energy efficiency of buildings}

Modern requirements for green buildings in terms of energy efficiency are as follows [1-4, 7, 8]:

1. Reducing the need for energy use - this refers to the use of architectural, engineering and structural energy-saving environmentally friendly solutions.

2. The use of renewable energy sources - this refers, first of all, to technical solutions for integrating solar collectors, heat pumps, biotechnologies, etc. into the building's energy supply system.

3. Optimal use of the requested energy. This is the most creative section, which involves energy comparison of various heating, ventilation, air conditioning, refrigeration technologies and mainly based on the results of mathematical modeling of the building as a single energy system.

As a matter of fact, the above ways of increasing the energy efficiency of buildings were known to a fairly narrow circle of specialists, as well as scientific, methodological technical principles for their implementation, described by these specialists.

\section{New knowledge for architect and engineer}

In this case, new knowledge consists in the fact that a system of new regulatory documents, a system of methodological and scientific developments, as well as training programs should be created. They will allow the specialist to achieve the goal of increasing the energy efficiency of buildings in accordance with the above requirements [4-8].

But the most important thing is that all specialists who want to meet the design requirements of the 21 st century in terms of creating a comfortable environmentally friendly human environment must undergo training and pass the appropriate certification exams. 
Reference books on "green buildings" list the following tasks that are included in the scope of work of an architect: orientation of the building to the cardinal points, location of the building in the site development, the choice of the shape of the building's shell, glazing and materials of the external fencing, considering the building as a single energy system, taking into account the directed action of the external climate. Buildings with natural ventilation should have such an orientation and location of the supply openings so that the air flow into the premises is ensured in different wind directions and during the calm period. Roofs of buildings of different heights are recommended to be planted with various plants in order to reduce the amount and level of storm water treatment.

As a matter of fact, these tasks were always in the field of architect's activity. The difference is that earlier these requirements were advisory, and their implementation was carried out depending on the ambitiousness of an architect. In accordance with the classification of "green buildings", points are added for good performance of each of these requirements.

In essence, certification of an object according to the "green buildings" system initiates a creative search of architects and engineers for such technical solutions that minimize the negative and optimize the positive impact of energy, environmental and technological factors that define the building as a human environment. Thus, it is difficult to separate the work of the architect and engineer: there is their joint activity throughout the design process, and only such a union can ensure success in achieving the goal.

In a typical design environment, these requirements are recommendations, and if you wish to receive a certificate, these recommendations become the requirements for which reward points are given. The question arises - how to implement these recommendations in the design of buildings in the best way?

This is where the architect and engineer need new knowledge. In this case, the concept of "new knowledge" is to give the designer a systematic view of energy-saving technologies, to justify the need for their creative application, taking into account the climate of the construction area, technological purpose of the building, and modern technical capabilities. This knowledge is based on a system of regulatory and methodological documents (which must be specially designed!), and the training of engineers and architects in using these documents, as well as on numerous well-known articles, studies. The latter suggests that institutes of such training with appropriate teachers should be created. After training, an architect or engineer receives the qualifications of an accredited specialist. Then, when participating in a tender for design, construction or operation, he receives an advantage, and the building receives additional points during certification.

Sometimes a negative attitude towards the certification system arises among investors who are very unfamiliar with the "green building" system, since, in their opinion, this leads to an increase in the cost of the facility. This is not entirely true or even not at all. Firstly, the commercial value of an object when renting or selling it is significantly higher than an uncertified building, since a truly certified object is a highly efficient building in terms of environmental comfort, environmental safety and minimizing energy consumption. For example, now in the US in times of crisis, real estate developers, while advertising houses built in accordance with strict environmental standards, state that green building technologies benefit not only the environment, but also the homeowner's wallet. Real estate buyers in the US listen to this argument like never before. Secondly, we can give a similar example with the development of PC: the capabilities and quality of computers increase every year, and their price decreases significantly. In addition, a computer purchased 3-4 years ago is already losing its consumer qualities and does not satisfy the consumer. 


\section{Green standards system}

We have developed a system of assessment standards based on the principles of green construction for residential buildings, public buildings, sports facilities, taking into account the climatic and economic features of various regions of Russia [4-6, 7-8].

In order to evaluate buildings according to the green construction system we have designed standard "Green construction. Residential and public buildings. Rating system for environment sustainability evaluation". This Standard contains requirements for energy efficiency and environmental performance of buildings, as well as for a building in general as the human environment.

Evaluation of a building as human environment is related not only to the construction facility itself, but to other parameters, including the meaning of "human environment", namely: availability of parking zones, sport and children's facilities, parking spaces for cars and bicycles near the building, distance to public transport stops, etc.

This standard is not the "final word" of the construction business development in Russia, but a road map that the construction industry must follow.

The construction society met this Standard positively. It is interesting for each link participating in the building life cycle - design, construction and operating organizations, investors, consumers, manufacturers of building materials, structures and engineering equipment.

A peculiarity of the Russian standard is that it contains 10 categories of the rating system of the environment sustainability. Categories and their weight are shown in Table 1.

Table 1 shows that the most important human environment rating criteria is "Energy saving and energy efficiency". This category includes energy consumption evaluation criteria by building utility systems individually and the total consumption of primary energy. Let's look at values of these criteria for multistory residential building.

Table 1. Categories of the human environment sustainability.

\begin{tabular}{|c|l|c|}
\hline No. & \multicolumn{1}{|c|}{ Category name } & $\begin{array}{c}\text { Category weight, } \\
\text { \% }\end{array}$ \\
\hline 1 & Comfort and quality of external environment & 10.8 \\
\hline 2 & Quality of architecture and facility planning & 9.2 \\
\hline 3 & Comfort and ecology of inner environment & 13.3 \\
\hline 4 & Quality of sanitary protection and waste disposal & 3.9 \\
\hline 5 & Rational water usage & 6.1 \\
\hline 6 & Energy saving and energy efficiency & 18.5 \\
\hline 7 & Use of alternative and renewable energy & 9.2 \\
\hline 8 & Facility creation, operation and disposal ecology & 9.8 \\
\hline 9 & Economic efficiency & 10 \\
\hline 10 & Quality or project preparation and management & 9.2 \\
\hline
\end{tabular}

The first criterion - Thermal energy consumption by heating and ventilation systems evaluates decrease in the specific thermal energy consumption by the heating system. Is basic specific consumption is a calculated value that serves as the benchmark for comparison publically acceptable consumption level and acceptable level for use in the mass construction.

The second criterion - Thermal energy consumption for the hot water supply system evaluates decrease in the basic specific thermal energy consumption rate by the hot water supply system.

The third criterion - Electricity consumption - is evaluated under the following criteria: decrease in the basic specific electricity consumption for building lighting, decrease in the 
basic specific electricity consumption for building utility systems, decrease in the basic specific electricity consumption for air conditioning system.

A separate evaluation is done for installation of power consuming equipment and electrical devices labeled not lower than the two top categories of energy efficiency.

The fourth criterion - total primary energy consumption for building energy supply systems - evaluated decrease in the basic specific consumption of primary energy for building utility systems.

Such approach allows for the most precise and diverse evaluation of green buildings, and its main advantage is possibility to optimize the energy transformation processes and minimize the consumption of primary energy resources for production of a unit of final energy-carrier.

"Comfort and ecology of inner environment" is the second important one in the rating system and includes "Control and management of building utility systems" criterion. This criterion evaluates availability of a centralized building control system with possibility of individual (zoned) regulation and local utility automation systems, which also helps to reduce power consumption through, for example selection of efficient thermal energy regulation algorithm for heating, taking into consideration room usage density, usage mode, preferences of users, etc. This category also includes the requirements for light, acoustic, air temperature comfort and protection of rooms from radon accumulation.

The third important is "Comfort and quality of outer environment" category that evaluates the parameters and conditions of the external environment, e.g. accessibility of public transportation and social infrastructure objects, greenery of the adjacent territory, proximity of water bodies, visual comfort, etc.

One should also note that the Standard lists economic requirements for the facility in "Economic efficiency" category. For example, "Value of reduced costs for the facility life cycle" criterion evaluates the share of specific reduced (discounted) total costs for the facility from the corresponding share for similar object, and "Value of annual operational costs" criterion evaluates the relation of mean annual operational costs (energy, water, maintenance, repairs) to the similar costs for a traditional equivalent facility.

"Ecology of creation, operation and disposal of facility" category set the following evaluation criteria: minimization of the effect from materials used in construction on the environment; minimization of waste from performance of construction works; measures aimed at protection and restoration of the environment during construction, as well as minimization of impact during operation and disposal of the building.

"Quality of facility architecture and planning" category contains "Supply of building with natural lighting" criterion, which evaluates the percentage of excess of regulatory coefficient of natural lighting inside building. This in turn provides for reduction of electricity consumption for lighting, as well as improvement of the human environment quality.

The same category contains "Optimal form and orientation of building" criterion allowing for evaluation of the thermal energy impact of the outside climate on the building envelope using the building's thermal performance factor. This coefficient is calculated as ratio of the minimum specific thermal energy consumption for building heating to the design consumption used during design. Such design approach allows for optimization of the positive and minimization of the negative impact of the external climate on the building envelope, thus leading to a decrease in the consumption of fuel and energy resources during the heating period.

This category also evaluates the quality of architectural appearance of the building, greenery around the building, sufficiency of useful area, comfort of space design solutions, and sufficiency of parking spaces. 
Moreover, the Standard set aside "Usage of alternative and renewable energy" category that evaluates the share of secondary and renewable energy in the facility's annual energy balance, thus helping to achieve high energy efficiency indicators and meeting the requirements for sustainable human environment.

Another important category is "Quality of project development and management". This category evaluates the designer's experience in design of green buildings, developer's (general contractor's) experience in construction of green buildings, and managing company's experience in operation of green buildings. Moreover this category contains "Performance of scientific research in preparation of the project" allowing for evaluation of simulation activities for optimization of energy efficiency in buildings and performance of alternatives' analysis of the human environment sustainability.

"Rational water use" category set the requirements for reduction of specific water consumption per person per year in relation to the regulatory value, and level of discharge treatment ("grey" discharge and storm waters).

Sanitary measures and waste treatment measures are evaluated in "Quality of sanitary protection and waste treatment" category: automated systems of antibacterial treatment, organization of primary waste sorting and system for disposal of mercury waste.

Overall the rating system requirements are aimed at reduction of the energy resources consumption, use of un-traditional, renewable and secondary energy resources, rational water consumption, reduction of hazardous impact on the environment during the building construction and operation, including adjacent territory, for creation of comfortable human environment and sufficient economic feasibility of architectural, construction and engineering solutions.

Depending on the number of points received from rating criteria a building receives human environment sustainability category and receives a certificate of compliance.

\section{Green certification of stadiums FIFA-2018}

The practical application of our developments was reflected in the preparation of our country for the FIFA-2018 World Cup. According to the requirements of international sports organizations, large international competitions, such as the Olympics or the World Cup, must be held only at certified stadiums. Therefore, certification of football stadiums according to the standards of "green" construction was a prerequisite for holding the World Cup in Russia in 2018.

Several rating systems for building certification have been developed and are operating in Russia. The most developed are rating systems created by NP "AVOK" by order of NOSTROY.

On the instructions of the Ministry of Natural Resources of the Russian Federation, the green standard "RUSO. Football stadiums" [8] was developed with the leading role of NP "AVOK". Let us note the important difference between this standard and the leading global rating systems: none of them has a standard designed specifically for rating football stadiums. The standard was reviewed by foreign experts and, after refinement, agreed with FIFA. The system "RUSO. Football stadiums" is recognized by FIFA as the official national system under which such certification can be performed. Using the system "RUSO. Football stadiums", we performed certification of stadiums in Kazan, St. Petersburg, Volgograd, Rostov-on-Don, Yekaterinburg, Kaliningrad, Samara, Nizhny Novgorod and Saransk.

In the certification system "RUSO. Football stadiums", an object is assessed according to 63 criteria, which contain 150 indicators. Criteria are grouped into 13 categories. At the first stage, an assessment is carried out on 12 mandatory criteria of the category "Preliminary mandatory requirements". 
Preliminary mandatory requirements correspond to the requirements of international green building standards (LEED, BREEAM, DGNB) and thus harmonize the national certification system "RUSO. Football stadiums" with international systems. The presence and mandatory fulfillment of these criteria is a FIFA requirement. These are such criteria as preventing environmental pollution during the construction of the facility, reducing water consumption for irrigation of the adjacent territory, reducing domestic water consumption, accounting for water consumption, monitoring compliance with the requirements for putting the facility into operation, the minimum level of energy efficiency of the facility, accounting for energy consumption, monitoring the use of ozone-safe refrigerants, sanitary protection and disposal of waste, disposal of construction waste, minimum level of thermalair comfort, control of smoking areas.

Only if the mandatory requirements are met, the object is assessed further by 51 criteria in 12 categories, according to which points are given. Experts make an assessment by 128 indicators. The final result is formed by summing up the gained points for the degree to which the criteria are met. The total maximum amount is 655 points. Certification is possible if a stadium gained 263 points or more. The system provides four certification classes: Green Building (263 to 343 points), Silver (344 to 425 points), Gold (426 to 544 points), Platinum (525 to 655 points).

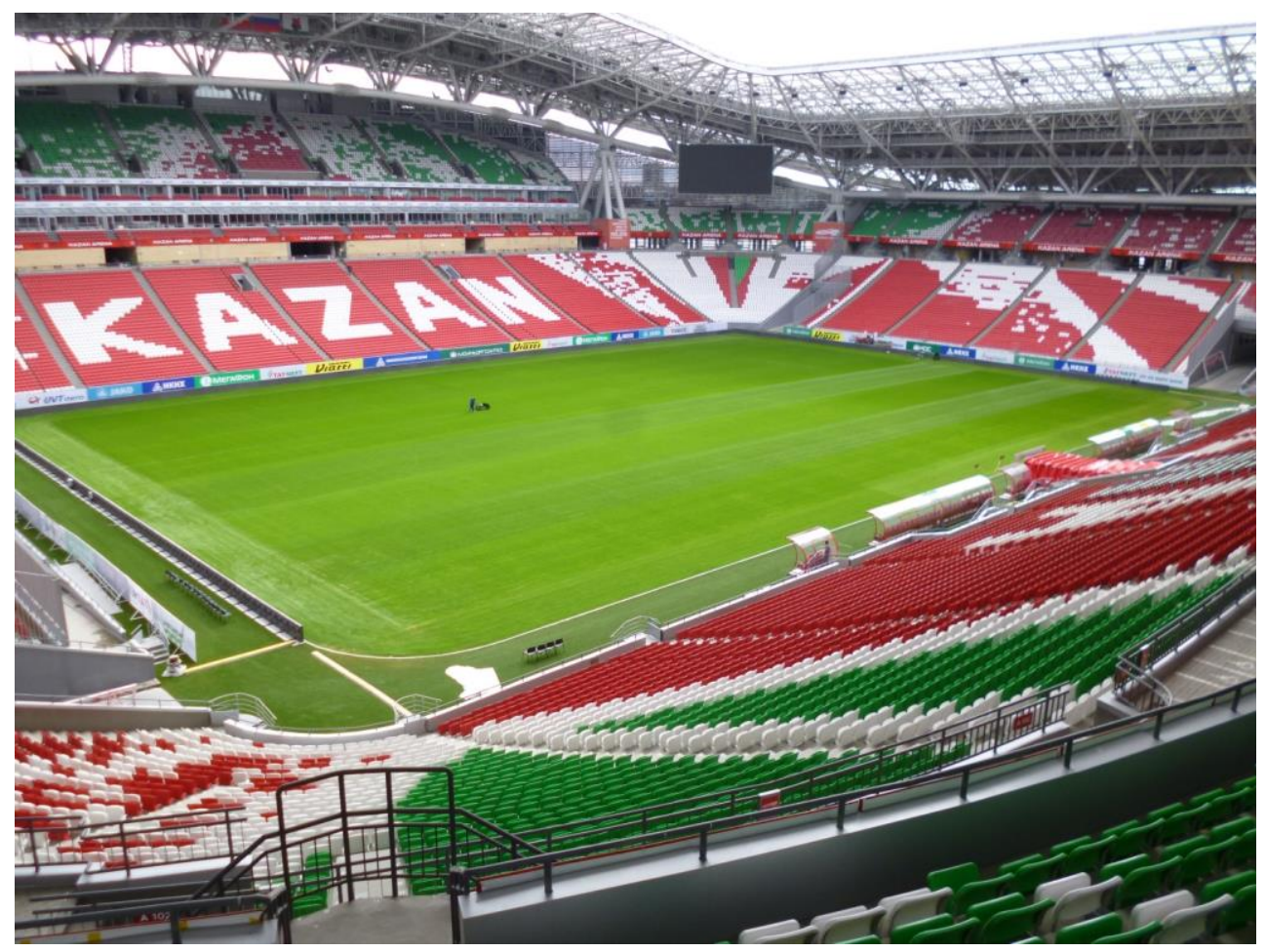

Fig. 1. Kazan Arena - one of the green stadiums FIFA-2018.

\section{Green education}

An important area in the development of green building is associated with the development of rating systems for assessing student architectural projects. Such a system of standards was developed and successfully used at the Moscow Architectural Institute: each student's work ends with its assessment according to the principles of green building. 


\section{References}

1. ANSI/ASHRAE/ICC/USGBC/IES Standard 189.1-2017 Standard for the Design of High-Performance Green Buildings

2. M. Bauer, P. Mozle, M. Schwarz, Green Building (Konzepte fur nachhaltige Architektur, 2007)

3. Russian State Standard GOST R 54964-2012 “Conformity assessment. Environmental requirements for real estate objects"

4. Industry Standard NOSTROY 2.35.4-2011 "Green Building”. Residential and public buildings. Environmental sustainability rating

5. Industry Standard NOSTROY 2.35.68-2012 "Green Building”. Residential and public buildings. Consideration of regional features in the rating system for assessing the sustainability of the environment

6. Industry Standard NOSTROY 2.35.153-2014 "Green Building”. Sports buildings and facilities. Consideration of features in the rating system for assessing the sustainability of the environment

7. RUSO 15.1-2017. Rules and procedure for rating certification of residential and public buildings

8. RUSO.FS 1.0-2016. Rules and procedure for rating certification of football stadiums 